\title{
Oral diclofenac potassium versus hyoscine-N-butyl bromide for pain relief during copper intrauterine device insertion: randomized clinical trial
}

\author{
Ahmed M. Abbas ${ }^{1 *}$, Mohammed F. Abdel-Ghany ${ }^{2}$, Nadia Abdullah Mohammed ${ }^{3}$, \\ Mostafa M. Khodry ${ }^{2}$, Armia Michael ${ }^{1}$, Laila E. Abdelfatah ${ }^{4}$, Hossam Ramadan $^{4}$
}

\begin{abstract}
${ }^{1}$ Department of Obstetrics and Gynecology, Faculty of Medicine. Assiut University, Assiut, Egypt
${ }^{2}$ Department of Obstetrics and Gynecology, Faculty of Medicine. South Valley University, Qena, Egypt

${ }^{3}$ Faculty of Nursing. South Valley University, Qena, Egypt

${ }^{4}$ Department of Obstetrics and Gynecology, Faculty of Medicine. Aswan University, Aswan, Egypt
\end{abstract}

Received: 19 December 2017

Accepted: 20 January 2018

\section{*Correspondence:}

Dr. Ahmed M. Abbas,

E-mail: bmr90@hotmail.com

Copyright: ( $)$ the author(s), publisher and licensee Medip Academy. This is an open-access article distributed under the terms of the Creative Commons Attribution Non-Commercial License, which permits unrestricted non-commercial use, distribution, and reproduction in any medium, provided the original work is properly cited.

\begin{abstract}
Background: Present study was carried out to compare the analgesic effect of oral diclofenac potassium versus hyoscine-N-butyl bromide (HBB) for pain relief during copper intrauterine device (IUD) insertion.

Methods: It was a a randomized clinical trial carried out at Assiut University Hospital, Assiut, Egypt. Parous women eligible for Copper IUD insertion were recruited and randomized in a 1:1 ratio to diclofenac potassium or HBB. The participants were asked to take 2 tablets of the study medications 30 minutes before IUD insertion. The primary outcome was the participant's self-rated pain perception using a 10-cm Visual Analogue Scale (VAS) during IUD insertion. We considered a $1.5 \mathrm{~cm}$ difference in VAS scores between study groups as clinically significant.

Results: One hundred eight women were enrolled ( $n=54$ in each group). Diclofenac significantly has lower mean pain score during speculum placement (1.73 vs. 2.13) and tenaculum placement (1.85 vs. 2.3) than HBB with $\mathrm{p}<0.001$. No statistical significant differences between both groups in other steps of IUD insertion. Additionally, the duration of IUD insertion was significantly lower in the diclofenac group $(5.34 \pm 0.76$ vs. $5.74 \pm 1.23$ minutes, p=0.045). No women reported side effects in both groups.

Conclusions: The use of oral diclofenac potassium 30 minutes prior to copper IUD insertion slightly reduce the insertional pain and duration than oral HBB with no adverse effects.
\end{abstract}

Keywords: Contraception, Diclofenac potassium, Hyoscine-N-butyl bromide, Intrauterine device

\section{INTRODUCTION}

Intrauterine device (IUD) is considered the most effective Long-acting reversible contraception (LARC) methods with lower incidence of failure compared with other reversible contraception methods. Though its effectiveness, it's still an underutilized method of contraception in developed countries. ${ }^{1}$ There are many causes that may contribute to the low prevalence of use of IUD. Fear of pain during IUD insertion is one of the most important factors which contribute underutilization of IUD and some gynecologists avoid using it in women with more risk for pain as nulliparous women., ${ }^{2,3}$

Different medications to minimize the pain during IUD insertion have been studied. These include medications 
which decrease cramping of the uterus such as nonsteroid anti-inflammatory drugs (NSAIDs), drugs that ripen the cervix, and drugs that numb the cervix by administration of local anesthetics. ${ }^{4-8}$ However, interpretation of the current data is limited and no consensus regarding administration of the optimal analgesic, timing or route. ${ }^{9}$

NSAIDs decrease pain and inflammatory reaction by blocking cyclooxygenase enzyme effect, and that leads to block formation of endogenous prostaglandins ${ }^{10}$. Complications of NSAIDs (e.g.: Upper gastrointestinal tract ulceration and perforation, renal injury...etc.) are more commonly to occur with prolonged use, and usually there are no risks if used over the short term. ${ }^{10}$

A recent Cochrane systematic review (2015) included seven trials on the efficacy of non-steroidal antiinflammatory drugs (NSAIDs) in reducing pain during IUD insertion. ${ }^{9}$ The efficacy of oral naproxen, ibuprofen and intramuscular ketorolac were tested with variable degrees of success. ${ }^{9}$ The effect of oral diclofenac potassium for pain relief during IUD insertion has not been evaluated.

Hyoscine n-butyl bromide (HBB) is an antispasmodic drug with peripheral anticholinergic effects on gastrointestinal, biliary and genitourinary system smooth muscle. ${ }^{12} \mathrm{HBB}$ has been commonly used for analgesic purposes in ureteral or renal colic, intestinal colic and labor analgesia. ${ }^{13}$

Previous studies on the analgesic effect of $\mathrm{HBB}$ during gynecological procedures reported no benefit during saline infusion sonohysterography (SIS), hysterosalpingo-contrast sonography (HyCoSy) and hysterosalpingography. ${ }^{14-16}$

Our hypothesis is that $\mathrm{HBB}$, a muscarinic receptor antagonist with anticholinergic effects, can reduce IUDassociated pain through relief of uterine spasms induced by insertion of the uterine sound and the IUD tube. To the best of our knowledge, no study has examined the efficacy of diclofenac potassium versus HBB on reducing IUD-associated pain.

Therefore, the current study aims to compare the analgesic effect of oral diclofenac potassium versus hyoscine-N-butyl bromide for pain relief during IUD insertion.

\section{METHODS}

The current study was a randomized, double-blind trial (ClinicalTrials.gov NCT02714231). The study was conducted Assiut Women Health Hospital, Egypt between February and October 2016. The Institutional Ethical Review Board approved the study, and we obtained a written informed consent from all participants before enrollment.
Women aged 18 years or older presented to the Family Planning Clinic asking for a copper IUD insertion as a contraceptive method were invited to participate in the study. We excluded women received any analgesics or misoprostol within 24 hours prior to insertion. Those with a Category 3 or 4 conditions for IUD insertion according to the WHO Medical Eligibility Criteria for contraceptive use were also excluded. Moreover, we excluded women declined participation in the study. ${ }^{17}$

A statistician, not otherwise involved in the study, prepared a computer generated random table and placed the allocation data in sequentially numbered opaque sealed envelopes. Each envelope had a card noting the group identifier inside. A single pharmacist was responsible packaging of both drugs in opaque sterile boxes with labeling them as $\mathrm{A}$ and $\mathrm{B}$. Only the Pharmacist knew what the medication in box $\mathrm{A}$ and $\mathrm{B}$ was, so neither the clinician nor the women knew the type of the preparation.

Once enrolled, the clinic nurse opened the envelopes according to the sequence of attendance of women. We randomized participants in a 1:1 ratio into one of two groups: (Diclofenac group) received two tablets of $25 \mathrm{mg}$ diclofenac potassium (Cataflam $®$; Novartis Pharma AG, Switzerland) and (HBB group) received two tablets of 10 mg HBB (Buscopan $®$; Boehringer ingelheim International $\mathrm{GmbH}$, Germany). All women were instructed to take the two tablets orally 30 minutes before the IUD insertion.

Before insertion, one of the study researchers collected the baseline data. Then, he explained the standard $10-\mathrm{cm}$ visual analog scale (VAS) to the participants for pain scoring. ${ }^{18}$ The severity of pain was assessed with VAS (with $0=$ no pain and $10=$ worst imaginable pain). Each woman received a copper T380A IUD (Pregna®T380A; Pregna International Ltd USA, Mumbai, India) for insertion. During IUD insertion, all women were menstruating. The day of the menstrual cycle ranged from the second to the fifth.

The IUD was inserted by one of the study investigators who have 10 years experience in IUD insertion using the standard technique of application. Firstly, the speculum was placed into the vagina and the cervix was cleansed with Povidone iodine. Then, traction was applied on the cervix using tenaculum and the uterine sound was introduced followed by the IUD insertion. Immediate complications as uterine perforation and vasovagal attack in addition to the duration of insertion were recorded.

A research assistant asked the women to rate the intensity of pain at five consecutive steps; at speculum placement, at tenaculum placement, at sound insertion, at IUD insertion and 5 minutes after the end of insertion using the same 10-point VAS with a different sheet of paper at every point. 
After the end of procedure, the clinician assessed the ease of IUD insertion using the ease of insertion score (ES). The ES is a graduated VAS-like scale from zero to 10; in which 10 means terribly difficult insertion and zero means very easy insertion. The ES was validated for use in previous similar studies about IUD insertion. ${ }^{7,8}$

At 15 minutes post insertion; all women were asked to report their level of satisfaction with IUD insertion by completing a $10-\mathrm{cm}$ VAS (with $0=$ no satisfaction and $10=$ maximum satisfaction). Also, they were asked about the need for additional analgesics. Finally, they reported any side effects occurred as a result of the medications used.

The primary outcome was the difference in mean pain VAS scores during IUD insertion. The secondary outcomes included the mean pain scores during speculum, tenaculum placement, sound insertion and 5 minutes post-insertion, the ease of insertion score, the women's satisfaction score, the duration of insertion, the need for additional analgesics and the side effects of the used medication.

The required sample size was calculated based on previous study by Bednarek et al reported that the mean VAS pain score with IUD insertion if placebo used was $4.3 \mathrm{~cm}^{19}$ We assumed that a clinically significant difference in VAS pain score is $1.5 \mathrm{~cm}^{20}$ Using a standard deviation of $2.6 \mathrm{~cm}$ to obtain $80 \%$ power with $\alpha$ error of 0.05 , a sample size of 54 women was needed in each group to detect $1.5 \mathrm{~cm}$ decrease in the VAS pain score with the use of diclofenac potassium or HBB assuming a rate of $10 \%$ drop-out cases (OpenEpi, Version 3, open source calculator-SSMean).

\section{Statistical analysis}

All data were analyzed using SPSS software Chicago, IL, USA, version 21. A Shapiro-Wilkes test was performed to test normality of the different pain scores. Data showed normal distribution, so they were presented as mean \pm standard deviation. Comparison between categorical variables in both groups was done by Chisquare test and continuous variables were compared using Student t-test. We considered $\mathrm{P}$ value $<0.05$ as a significant value.

\section{RESULTS}

One-hundred fifty-three women were approached to participate in the study.

Ten women have been excluded; six of them had received analgesics prior to insertion and four women were not eligible for insertion. Moreover, three women declined participation in the study. We randomly assigned the remaining 140 women into both groups (Figure 1).

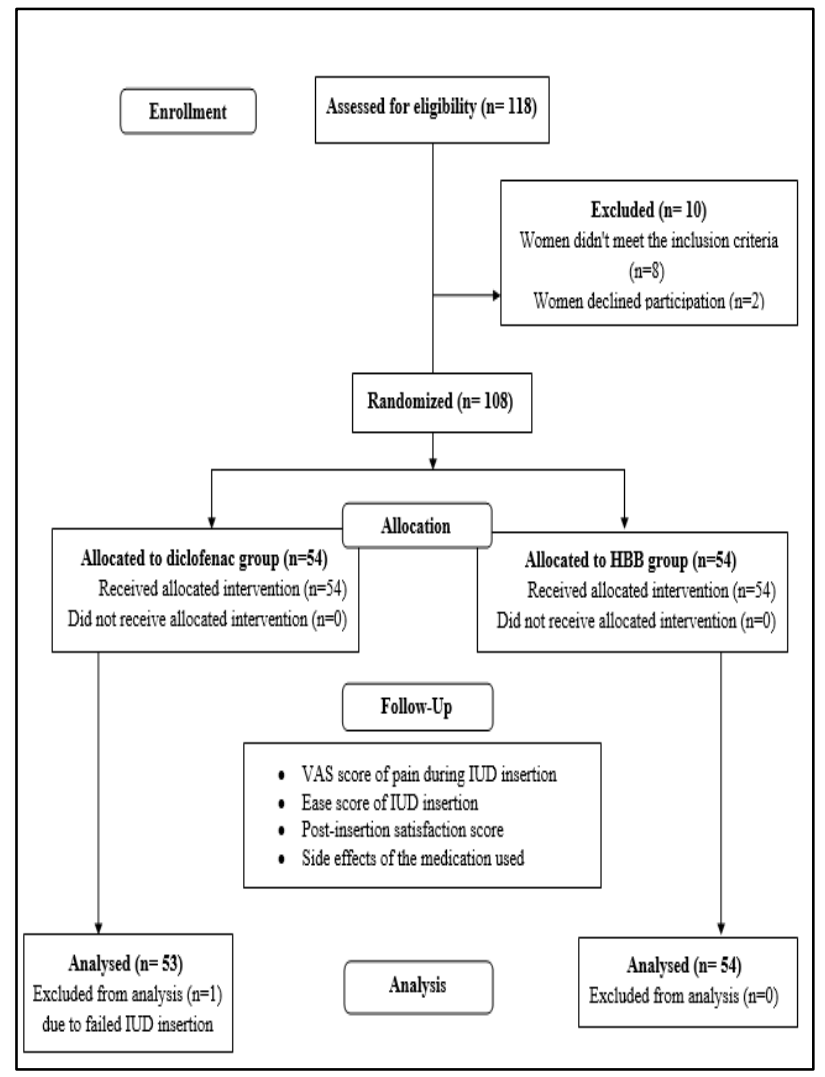

Figure 1: Flowchart of the study participants.

Baseline characteristics of the study participants are presented in Table 1. Both groups were comparable with regard the age, residence, educational level, parity, previous miscarriages, vaginal deliveries, cesarean deliveries, previous IUD insertion and history of dysmenorrhea.

Table 2 shows the mean pain scores for both groups. Women in diclofenac group reported lower pain scores during speculum placement $(1.73 \pm 0.79$ vs. $2.13 \pm 1.17$, $\mathrm{p}=0.044)$ and tenaculum placement $(1.85 \pm 0.82$ vs. $2.30 \pm 1.26, \mathrm{p}=0.033)$ than HBB group. However, this difference was not of clinical significance. No statistical significant differences between both groups in other steps of IUD insertion.

The mean satisfaction scores were $7.33 \pm 1.14$ and $6.38 \pm 2.24$ in the diclofenac and HBB groups respectively $(\mathrm{p}=0.007)$. A lower ease of insertion score was observed among diclofenac group (1.30 \pm 0.69 vs. $2.17 \pm 1.25)$ with statistical significant difference $(\mathrm{p}=0.015)$. Additionally, the duration of IUD insertion was significantly lower in the diclofenac group $(5.34 \pm 0.76$ vs. $5.74 \pm 1.23$ minutes, $\mathrm{p}=0.045$ ).

Ten women asked for additional analgesics in the HBB group versus four in the diclofenac group $(\mathrm{p}=0.15)$. No cases of uterine perforation or vasovagal reactions were observed in both groups. Also, no women reported side effects in both groups (Table 2). 
Table 1: The baseline characteristics of the women according to the medication used prior to IUD insertion.

\begin{tabular}{|c|c|c|c|}
\hline Characteristics & Diclofenac group, $(\mathrm{n}=53)$ & Hyoscine group, $(n=54)$ & P-value \\
\hline \multicolumn{4}{|l|}{ Age (years) } \\
\hline Mean \pm SD & $30.66 \pm 6.65$ & $29.93 \pm 6.28$ & 0.558 \\
\hline \multicolumn{4}{|l|}{ Residence, n (\%) } \\
\hline Urban & $36(67.9)$ & $31(57.4)$ & \multirow{2}{*}{0.319} \\
\hline Rural & $17(32.1)$ & $23(42.6)$ & \\
\hline \multicolumn{4}{|l|}{ Education, n (\%) } \\
\hline Illiterate & $11(20.8)$ & $11(20.4)$ & \multirow{4}{*}{0.071} \\
\hline Primary education & $26(49.1)$ & $22(40.7)$ & \\
\hline Secondary education & $16(30.1)$ & $14(25.9)$ & \\
\hline University education & 0 & $7(13)$ & \\
\hline Parity, Mean \pm SD & $2.77 \pm 1.39$ & $3.06 \pm 1.55$ & 0.325 \\
\hline \multicolumn{4}{|l|}{ Previous miscarriages } \\
\hline Mean \pm SD (range) & $13(24.5)$ & $14(25.9)$ & ---- \\
\hline Previous VD, n (\%) & $29(54.7)$ & $38(70.4)$ & 0.112 \\
\hline Previous CD, n (\%) & $33(62.3)$ & $25(46.3)$ & 0.122 \\
\hline \multicolumn{4}{|l|}{ Number of CD } \\
\hline Mean \pm SD (range) & $1.15 \pm 0.74$ & $1.11 \pm 0.99$ & 0.074 \\
\hline Previous insertion of IUD, $\mathrm{n}(\%)$ & $23(43.4)$ & $28(51.9)$ & 0.441 \\
\hline Dysmenorrhea, $\mathrm{n}(\%)$ & $13(24.5)$ & $7(13)$ & 0.147 \\
\hline
\end{tabular}

VD; vaginal delivery, CD; Cesarean delivery, IUD; intrauterine device, SD; standard deviation,

Table 2: The principal outcomes during IUD insertion according to the medication used prior to the procedure.

\begin{tabular}{|c|c|c|c|}
\hline Study Outcomes & Diclofenac group, $(n=53)$ & Hyoscine group, $(\mathrm{n}=54)$ & P-value \\
\hline VAS speculum placement, Mean \pm SD & $1.73 \pm 0.79$ & $2.13 \pm 1.17$ & $0.044^{*}$ \\
\hline VAS tenaculum placement, Mean \pm SD & $1.85 \pm 0.82$ & $2.30 \pm 1.26$ & $0.033^{*}$ \\
\hline VAS sound insertion, Mean \pm SD & $2.08 \pm 1.17$ & $2.13 \pm 1.06$ & 0.803 \\
\hline VAS IUD insertion, Mean \pm SD & $3.66 \pm 0.87$ & $3.94 \pm 0.99$ & 0.105 \\
\hline VAS 5 minutes post-insertion, Mean \pm SD & $1.42 \pm 0.93$ & $1.70 \pm 0.79$ & 0.071 \\
\hline Ease of insertion score, Mean \pm SD & $1.30 \pm 0.69$ & $2.17 \pm 1.25$ & $0.019 *$ \\
\hline Satisfaction score, Mean \pm SD & $7.33 \pm 1.14$ & $6.38 \pm 2.24$ & $0.007^{*}$ \\
\hline Duration of insertion (min), Mean \pm SD & $5.34 \pm 0.76$ & $5.74 \pm 1.23$ & $0.045^{*}$ \\
\hline Need for additional analgesics, n (\%) & $4(7.5)$ & $10(18.5)$ & 0.15 \\
\hline Uterine perforation, $\mathrm{n}(\%)$ & 0 & 0 & ------ \\
\hline Side effects of study medication, n (\%) & 0 & 0 & ------ \\
\hline
\end{tabular}

VAS; visual analog scale, IUD; intrauterine device, SD; standard deviation, $\left(^{*}\right)$ statistically significant difference

\section{DISCUSSION}

In the present study, intake of $50 \mathrm{mg}$ oral diclofenac potassium 30 minutes prior to copper IUD insertion reduces pain only at speculum and tenaculum placement more than oral HBB. This is the first study to compare the efficacy of oral diclofenac potassium and HBB as analgesics during IUD insertion.

Fear of pain during IUD insertion can be a barrier to its use. Thus, better pain control during insertion could lead to more widespread IUD use and decrease the rate of unplanned pregnancies as it is safe, highly effective, long-term and reversible contraceptive method. ${ }^{21}$

The optimal method for IUD insertion pain relief is still debatable. Lopez et al., 2015 in the Cochrane systematic review reported 7 randomized control trials included both oral and intramuscular NSAIDs ${ }^{9}$, six studies showed no difference in pain relief between women NSAIDs or placebo, while only one study on oral naproxen sodium showed an effective analgesic result on IUD insertion. ${ }^{22}$

Fouda et al reported that the use of oral diclofenac potassium combined with $2 \%$ lidocaine gel slightly reduced pain scores during tenaculum application and copper IUD insertion; however the reduction in pain scores has no clinical significance. ${ }^{23}$ In present study, the reduction in pain scores with diclofenac potassium use was more than HBB; however no clinical significance between the pain scores of both drugs also.

On the contrary, Abbas et al., 2017 reported in their study on oral diclofenac potassium plus lidocaine cream 
significantly reduction of the VAS pain scores during injection of the dye ( 4 vs. 7), and up to 30 minutes postprocedure (1 vs. 2.5) with $\mathrm{p}=0.0001$. No significant differences in VAS score after speculum or tenaculum placement. $^{24}$

HBB is an antispasmodic drug used for relief of muscle spasms. Its main action through blocking the transmission of neural impulses in the pelviabdominal parasympathetic ganglia and inhibiting the cholinergic transmission in the synapses, thus relieving spasm in the smooth muscles of urinary, biliary, gastrointestinal tracts and female genital organs. $^{24}$

A literature search reveals previous two studies evaluating the analgesic effect of HBB during office gynecological procedures. Jareethum et al had evaluated its effect during SIS procedure. ${ }^{14}$ They reported no statistical significant differences neither during SIS (median VAS; 5 vs. 4.5 in the HBB and placebo group, respectively, $\mathrm{p}=0.755)$. Also, satisfaction scores were similar (mean score; $9.20 \pm 1.31$ vs. $9.13 \pm 1.00$ in the HBB and placebo group, respectively, $\mathrm{p}=0.402$ ). Additionally, Moro et al evaluated the efficacy of $\mathrm{HBB}$ in reducing pain during HyCoSy; there was no statistically significant difference in pain scores between the HBB group and the placebo group $(\mathrm{p}=0.807) .{ }^{15}$

The main strength of our study is the randomized design. We were able to recruit our calculated sample size for achieving adequate power to detect a clinically significant difference in our primary outcome. Additionally, the study was conducted at the same clinic, with a single provider to avoid any inter-assessor variation in VAS scores estimation. Finally, we used validated pain scores and assessed women satisfaction, which was not assessed in many other trials. The main limitation of our study is the subjectivity in reporting pain through VAS score, even though it is the widely accepted method and there are currently no other objective parameters to evaluate pain.

\section{CONCLUSION}

In conclusion, oral diclofenac potassium intake 30 minutes prior to copper IUD insertion slightly reduces the insertional pain and duration than oral HBB with no adverse effects. Further large randomized trials are needed to compare its analgesic effect with other NSAIDs.

Funding: No funding sources Conflict of interest: None declared

Ethical approval: The study was approved by the Institutional Ethics Committee

\section{REFERENCES}

1. Kulier R, O'Brien PA, Helmerhorst FM, Usherpatel $\mathrm{M}$, D'Arcangues C. Copper containing framed IUDs for contraception. Cochrane Database Syst Rev. 2007;4:CD005347.

2. Allen RH, Goldberg AB, Grimes DA. Expanding access to intrauterine contraception. Am J Obstet Gynecol. 2009;201:451-5.

3. Weston MR, Martins SL, Neustadt AB, Giliam ML. Factors influence uptake of IUDs among postpartum adolescents: a qualitative study. Am J Obstet Gynecol. 2012;206:40.e1-40.e7.

4. Hubacher D, Reyes V, Lillo S, Zepeda A, Chen PL, Croxatto H. Pain from copper intrauterine device insertion: randomized trial of prophylactic ibuprofen. Am J Obstet Gynecol. 2006;195:1272-7.

5. Ahmed MA, Abdelrahman MA, Ahmed HE, Shaimaa A, Mohamed SF. Rectal indomethacin is an effective analgesic during copper T380A intrauterine device insertion: A randomized double-blind placebo-controlled trial. Glob J Reprod Med. 2017;2(1):555576.

6. Khalaf M, Amin AF, Sayed Z, El-Nashar IM, Abbas AM. A randomized double-blind controlled trial of two different doses of self-administered vaginal misoprostol for successful copper intrauterine device insertion, Middle East Fertil Soc J. 2017;22(4):2648.

7. Abdellah MS, Abbas AM, Hegazy AM, El-Nashar IM. Vaginal misoprostol prior to intrauterine device insertion in women delivered only by elective cesarean section: a randomized double-blind clinical trial. Contraception. 2017 Jun;95(6):538-43.

8. Abbas AM, Abdellah MS, Khalaf M, Bahloul M, Abdellah NH, Ali MK, et al. Effect of cervical lidocaine-prilocaine cream on pain perception during copper T380A intrauterine device insertion among parous women: A randomized double-blind controlled trial. Contraception. 2017;95(3):251-6.

9. Lopez LM, Bernholc A, Zeng Y, Allen RH, Bartz D, O'Brien PA, et al. Interventions for pain with intrauterine device insertion. Cochrane Database Syst Rev. 2015;29;7:CD007373.

10. Derry C, Derry S, Moore RA, McQuay HJ. Single dose oral naproxen and naproxen sodium for acute postoperative pain in adults. Cochrane Database Syst Rev. 2009;21(1):CD004234.

11. Mason L, Edwards JE, Moore RA, McQuay HJ. Single-dose oral naproxen for acute postoperative pain: a quantitative systematic review. BMC Anesthesiol. 2003;3:4.

12. Hotwani J, Ainapure SS. Hyoscine butylbromide suppositories. Indian Med Gaz. 2000;1:217-9.

13. Papadopoulos G, Bourdoumis A, Kachrilas S, Bach C, Buchhloz N, Masood J. Hyoscine Nbutylbromide (Buscopan ${ }^{\circledR}$ ) in the treatment of acute ureteral colic:what is the evidence? Urol Int. 2014;92:253-7.

14. Jareethum R, Suksompong S, Petyim S, Prechapanich J, Laokirkkiat P, Choavaratana R. Efficacy of mefenamic acid and hyoscine for pain relief during saline infusion sonohysterography in infertile women: a double blind randomized 
controlled trial. Eur J Obstet Gynecol Reprod Biol. 2011;155:193-8.

15. Moro F, Selvaggi L, Sagnella F, Morciano A, Martinez D, Gangale MF et al. Could antispasmodic drug reduce pain during hysterosalpingo-contrast sonography (HyCoSy) in infertile patients? A randomized double-blind clinical trial. Ultrasound Obstet Gynecol. 2012;39:260-5.

16. Abbas AM, Abo-Elela NA, Mosa EM. Effect of oral hyoscine-N-butyl bromide on pain perception during hysterosalpingography: a randomized, double-blind, placebo-controlled trial. Middle East Fertil Soc J. 2017 (Article in press).

17. World Health Organization. Medical Eligibility Criteria for Contraceptive Use. Geneva (Switzerland): WHO; 2010.

18. Bouhassira D, Attal N, Alchaar H, Boureau F, Brochet B, Bruxelle J, et al. Comparison of pain syndromes associated with nervous or somatic lesions and development of a new neuropathic pain diagnostic questionnaire (DN4). Pain. 2005;114(12):29-36.

19. Bednarek PH, Creinin MD, Reeves MF, Cwiak C, Espey E, Jensen JT, et al. Prophylactic ibuprofen does not improve pain with IUD insertion: a randomized trial. Contraception. 2015;91:193-7.

20. Rowbotham MC. What is a 'clinically meaningful' reduction in pain? Pain. 2001;94:131-2.
21. Potter J, Rubin SE, Sherman P. Fear of intrauterine contraception among adolescents in New York City. Contraception 2014;89:446-50.

22. Karabayirli S, Ayrim AA, Muslu B. Comparison of the analgesic effects of oral tramadol and naproxen sodium on pain relief during IUD insertion. J Minim Invasive Gynecol. 2012;19:581-4.

23. Fouda UM, Salah Eldin NM, Elsetohy KA, Tolba HA, Shaban MM, Sobh SM. Diclofenac plus lidocaine gel for pain relief during intrauterine device insertion. A randomized double blinded placebo-controlled study. Contraception. 2016;93(6):513-8.

24. Abbas AM, Wagdy WM, Salem MN, Abdelqader AM. Effect of oral diclofenac potassium plus cervical lidocaine cream on pain perception during hysterosalpingography: a randomized, double-blind, placebo-controlled trial. Middle East Fertil Soc J. 2017 (Article in press).

Cite this article as: Abbas AM, Abdel-Ghany MF, Mohammed NA, Khodry MM, Michael A, Abdelfatah LE et al. Oral diclofenac potassium versus hyoscine-N-butyl bromide for pain relief during copper intrauterine device insertion: randomized clinical trial. Int J Reprod Contracept Obstet Gynecol 2018;7:783-8. 